International Journal of Library \& Information Science (IJLIS)

Volume 8, Issue 2, May-August 2019, pp. 9-22, Article ID: IJLIS_08_02_002

Available online at

http://iaeme.com/Home/issue/IJLIS?Volume=8\&Issue2

Journal Impact Factor (2019): 9.8614 (Calculated by GISI) www.jifactor.com

ISSN Print: 2277-3533 and ISSN Online: 2277-3584

(C) IAEME Publication

\title{
A RESEARCH STUDY ON THE ROLE OF LIBRARY IN THE PRESERVATION OF CULTURE
}

\author{
Kyarimpa Jovuret and Athieno Florence \\ Bishop Stuart University, Mbarara-Uanda
}

\begin{abstract}
ABTRACT
Libraries, archives, and museums hold disparate collections in a variety of media, presenting a vast body of knowledge accumulated over the institutions' history, and the mission of these institutions is to make their collections accessible to intended users. Then the question, what are the roles of library and information science professionals in the preservation of cultural heritage? This becomes relevant question here
\end{abstract}

Key words: Library, Research, Culture, Preservation

Cite this Article: Kyarimpa Jovuret and Athieno Florence, A Research Study on the Role of Library in the Preservation of Culture, International Journal of Library \& Information Science, 8(1), 2019, pp. 9-22.

http://iaeme.com/Home/issue/IJLIS?Volume=8\&Issue2

\section{INTRODUCTION}

This research is an investigation on the use of the role of library in culture preservation.

Libraries, archives, and museums hold disparate collections in a variety of media, presenting a vast body of knowledge accumulated over the institutions' history, and the mission of these institutions is to make their collections accessible to intended users. Then the question, what are the roles of library and information science professionals in the preservation of cultural heritage? This becomes relevant question here.

\section{Background}

There are several roles that Librarians may play in digital libraries as implementers of unique materials in special collections (a role also played by museums and archives). Librarians are providers of such services as "virtual reference, preservation and indexing, and as managers and facilitators of scholarly communications, through their participation in establishing institutional repositories". Lynch (2002)

Book and Vondracek (2006) highlighted several past involvements of libraries in the preservation of documents to enhance access since medieval times when monks fastidiously transcribed documents by hand. They also indicated that libraries began massive newspaper 
microfilming and digitization projects to successfully reformat thousands of rare collections and crumbling newspapers as effective means of preserving print holdings. They further noted that digitization can also be the first step in conducting advanced research on historical materials and ancient documents present a prime candidate for digitization because of their historical imports, combined with century of exposure and degradation

Hundreds of libraries, museums and archives have recently launched projects designed to digitize their collections and place them on the web. According to Stephen Ostrow cited by Jones (2001), this trend is both "auspicious and ominous for cultural heritage institutions". The main reasons to digitize are to enhance assess and improve preservation. By digitalizing their collections, cultural heritage institutions can make information that was previously only available to a select group of researchers accessible to all. Digital projects allow users to search collections rapidly and comprehensively from anywhere at any time (Jones 2001).

One of the primary problems confronting library profession is lack of commitment by the available human resources, particularly, in the areas of information and communication technologies (ICTs) and preservation of resources on cultural heritage. The knowledge explosion brought about by the acceleration of scientific and technological progress is adding a new dimension to education, capacity building, amongst other essential human development endeavors. Librarians, irrespective of their levels in the professional hierarchy must possess the conceptual knowledge, skills and attitudes relevant to the performance of their jobs. Training refers to the manifestation of knowledge, skills and attitudes in a person which enables him to apply them in his work situation. In essence, education is to cause a permanent change in behavior potential of the concerned individual and it is regarded as the key with which to unlock the stores of knowledge and for their use by the society. As a result of its importance for professional upliftment, libraries have often tried to inculcate some desirable professional orientations in their personnel through training.

Digitization can also be the first step for conducting advanced research on historical materials. Ancient documents present a prime candidate for digitization because of their historical import, combined with centuries of exposure and degradation habits in their arrangement. However, Oketunji (2001) observed that the library schools are inadequate in meeting the challenges of modern information technologies owing to lack of financial resources to procure the necessary equipment needed for the training of students. Similarly, Singh (2004) argued that skill in information Technology (IT) can be gained only when one gets hands on training and experience in laboratories under simulated conditions or in real life situations. The graduates and past graduates turned out by library schools do not possess adequate skill and expertise to interact confidently with IT specialists, evaluate what is recommended by their and full fall their requirements.

\section{Statement of the problem}

Efforts to preserve resources on cultural heritage have gained new momentum throughout the world nowadays. Protecting cultural heritage is economical, as well as historical and also a cultural process. While cultural heritage preservation has not yet become firmly rooted in the Ugandan consciousness as football is, a great number of people and organizations see cultural resources as critical to the nation's economic development through tourism. Cultural heritage is based on the aspects of our past that we cherish, want to keep and pass on to future generations and outside world. Libraries, archives, and museums hold disparate collections in a variety of media, presenting a vast body of knowledge accumulated over the institutions' history, and the mission of these institutions is to make their collections accessible to intended users. Then the question, what are the roles of library in the preservation of cultural heritage becomes relevant here and is the trigger behind this study. 


\section{Purpose of the study}

The purpose of this study was to analyze the role of public library and digital systems in the preservation of culture in Mbarara district.

\section{Objectives of the study}

The objectives of the study are:

- To discover the role of public libraries and digital systems in the preservation of culture.

- To examine how libraries create access to indigenous knowledge.

- To investigate the challenges of preservation and accessibility of indigenous knowledge and their solutions.

\section{Research questions}

- What is the role of public libraries and digitalized system in the preservation of culture?

- How do libraries create access to indigenous knowledge?

- What challenges are faced in the preservation and accessibility of indigenous knowledge and what can be their solutions?

\section{Scope of the study}

The study was conducted in three university libraries in Mbarara district.

\section{Significance of the study}

1. The study will help library managers to put emphasis on the Training of Librarians. With the sporadic changes in the information network, it is absolutely imperative that continuing professional development of librarians should be given priority. Since these librarians serve divergent needs of users in their respective libraries, it is important that these professionals should be conversant with how to preserve and access relevant information. So management should consider this important function of developing their personnel to ensure effective service delivery.

2. The study will awake government stake holders to Provide infrastructure - Every organization stands on three pillars of capital, human and material resources to support its functions. For the library to develop properly they need not only human but also material resources such as infrastructure which will help the library to carry out its operations. For instance, librarians need to be trained on digitization of library materials; for the training to be effective, the necessary facilities for effective learning should be available. Also when the training has been completed, they need these skill enhancing facilities to work with for permanence of the knowledge and skills acquired during the learning process.

3. The study will help library stake holders to give adequate funding - for the effective functioning of the library, adequate fund is needed especially to get the best out from the two other factors (human and material resources). Where adequate fund is provided, training of librarians and equipping of the library will be effectively achieved and this will enhance the whole process of digitization of library materials.

4. Environmental conditions constitute a lot to the preservation of library resources. Both harsh and humid weather adversely affects library materials. To ensure the preservation of the cultural heritage resources, they should be stored in air-conditioned rooms with moderate the temperature and electric fans to avoid hotness of the environment. 


\section{REVIEW OF RELATED LITERATURE}

\section{Introduction}

Preservation of cultural heritage resources have long been a challenge for libraries. Numerous articles discussing training of librarian on preservation role is now recognized as one of the major processional responsibilities of librarians. The most significant reason for this reorientation of attitudes is the way manner and rate our resources deteriorate. In addition, other studies have examined digitization of cultural heritage resources.

The review of literature of the study will be discussed under the following sub-headings:

\section{A. The role of public libraries in culture preservation.}

Culture is a term used by social scientists for a way of life. Every human society has a culture. Culture includes a society's arts, beliefs, customs, institutions, inventions, language, technology, and values. Culture produces similar behavior and thought among most people in a particular society. This definition of culture is adopted by Linton (1945) who says: the culture of a society is the say of life of its members; the collection of ideas and habits which they learn; share and transmit from generation to generation (world Book Encyclopedia 2004)

The public library over the years has always played a pivotal role in equipping users with information and knowledge which have developed them for lifelong learning. IFLA/UNESCO Manifesto, 1994 alluded that a public library is a local gateway to knowledge and it is a provider of basic condition for lifelong learning, independent decision making and cultural development of an individual and social groups. This simply means that as the community uses the public library they access information which in turn make them socially fit in their society and on top of that are able to make right decisions in life. Among the key roles of the public library lies its role as a keeper of cultural information. The public library should provide a focus for cultural and artistic development in the community. It should help to shape and support the cultural identity of the community it serves. In order to achieve this goal public librarians should collaborate with stakeholders in their communities as well as different organizations, sectors so as to work together in gathering cultural collections. Key people in the community who mostly include chiefs and some elderly people are very relevant in sharing culture of the past. The materials collected should reflect the cultures found in the community. (IFLA/UNESCO Manifesto, 1994). This paper posits that one of the mandates of the public library among others is to collect and preserve cultural sources for posterity. If it does not do this, the community will lose its traditional identities hence the future generation will have nothing to refer to.

According to Dim and Osade be (2009) an endangered society is the one which loses its identity as a result of loss of its cultural heritage, and preserving cultural heritage of the communities it serves for posterity is a must for public libraries as cultural heritage contains the strengths and weaknesses of the community served. Simply put, public libraries are to keep cultural information sources for their communities so that they can always refer to them whenever need arises.

Public Libraries are meant to inspire lifelong learning, advance knowledge, and strengthen our communities. First and foremost, if public libraries do not document cultural heritage it will be lost and this means that their national identity will be lost. Public libraries are to preserve culture in order to show support for the cultural identity of the community. As public libraries collect and document cultural artifacts they are helping their communities to archive their past to be used in the future. Public libraries must document cultural heritage so that researchers may access it as they conduct their studies. These studies are mostly imperative because they can be read by the future generation. Bolt (2014) Just like archival centers, 
public libraries keep societal participation in them because they come to access their cultural sources. On the other hand if public libraries are store houses for cultural materials they will at the same time be attracting their communities to the library; this will mean that cultural sources in the library will call for usage by all including the elderly.

\section{B. Access to indigenous knowledge in the library.}

Ranasinghe (2008) defines Indigenous Knowledge (IK) as a corpus of knowledge belonging to a particular geographic area. It is also seen to contrast with knowledge generated within the international system of universities, research institutions and private firms (IK Papers, 2005). It is the unique, traditional and local knowledge existing within and developed around specific conditions of women and men indigenous to particular geographic area (Grenier, 1998). IK comprises of many parts ranging from culture, religion, mythologies, economy, governance, medicine, and agriculture to taboos, poetry, art and crafts and many more. It is often related to oral history, oral archives and oral tradition.

Indigenous Knowledge Systems are thus, the collection of interrelated practices peculiar to people in a specific place. No one indigenous system is superior to the other. Broadly, the knowledge systems include: agriculture, medicine, economy, governance, culture, worship and religion, conservation of natural resources. They are all interrelated and influence the lifestyle of local people.

Aina (2004) defines library and information centers as the institutions responsible for the collection, processing and storage of recorded knowledge for the purpose of reading, study and consultation; and the librarian as the professional who is concerned with the collection, storage, processing and dissemination of recorded knowledge in a library. This underlines the management of information and knowledge resources, which Mabawonku (2002) reports to include selection, collection, production, documentation, organization, preservation, dissemination and exchange.

Okore, et al., (2009) state that: Though there is so much indigenous knowledge in different indigenous communities of the developing world, the availability of such knowledge does not mean its accessibility or use. Libraries can promote access to indigenous knowledge by creating an environment which permits face-to-face forums and network formation to discuss and debate on issues that might be useful to members of the communities. For example, libraries can organize talk shows involving traditional rulers, elderly people and professionals to gather and record information on various local vocations from different subject areas ranging from agriculture, ecosystem, medical care, and conflict resolution. They go on to point out that, "libraries can work in partnership with library schools to create indigenous knowledge collections, which can be repackaged and made accessible." Stevens (2008) believes that libraries and information professionals should partner with indigenous communities. Ngulube (2002), however, observes that libraries have not been particularly active in managing IK. Nakata and Langton (2005) suggest that libraries and archives must look at the broad issues involved in the preservation of indigenous knowledge. They assert that libraries must consider Indigenous knowledge not simply part of a historical archive, but a contemporary body of relevant knowledge. There is therefore the need to provide ICTs such as computers, Internet, digital cameras, camcorders, and so on, to allow libraries to make Indigenous knowledge accessible 
Kyarimpa Jovuret and Athieno Florence

\section{Challenges and Solutions faced in preservation and accessibility of indigenous knowledge.}

\section{Training of Librarians}

Ducker (2000) sees training as a systematic process of altering the behaviour and/or attitudes of employees in a direction to increase organizational goal. Librarians, irrespective of their levels in the hierarchy, must possess the conceptual. Similarity, Appleby (1991) reiterates that the purpose or objectives of any training programmes should reflect the basic knowledge for the job which usually comes from education. He also noted that good training programmes should include skill and experience acquisition it should include development and conditions of attitudes and patterns of behavior of employees.

Much writing on the state of professional librarian's training in most Third World Countries including Nigeria constitutes a library of woes, which can be a summarized as lack of equipment, poor funding, inadequate manpower. These are interlinked and are generally blamed on a variety of problems external to the library itself, such as lack of government policies supporting libraries, this of courses lead to poor services to our users. As rightly observed by Ogunseye (1984) "developing countries such as Nigeria" cannot afford the luxury of training passive librarians only. According to him, we need librarians who are also information specialists and information brokers.

According to Singh (2004); the graduates and postgraduates turned out by library schools do not possess adequate skills and expertise to interact confidently with Information Technology (IT) specialists, evaluate what is recommended by them and fulfill their requirements. Singh (2004) further said that the developments in library and information curricula have serious implications for library and information science education. As a result, it has become imperative to incorporate appropriate components of Information Technology in LIS education if the profession intends to retain its identity. He further observed that few library schools have responded to this challenge by expanding teaching areas and including integration of computer applications into their information systems in order to prepare for the turning out of professionals that are capable of functioning in non-traditional settings.

Training has long been regarded as the bedrock of achieving quality productivity in any profession.

However, Agidatum (2007) argued most convincingly, there are professional librarians in the university libraries in Africa whose knowledge of library automation has been rendered obsolete owing to lack of training and re-training courses, which development poses challenges to their coping with modern library practices. This unpleasant trend is unfavorable to the development of library automation in Ugandan university libraries.

Appleby (1991) identified the following as the basic primary methods of employee training: on-the-job-training, apprenticeship training, vestibule training and classroom training methods.

Educating librarians about preservation is now widely recognized as an essential element of any plan to address the preservation problems. According to Harvey (1993), preservation education courses for library professionals are typically in one of three formats: as a part of compulsory course such as library administration in a first professional qualification; an optional course of about one semester; or a separate qualification, for example one or twoyear courses in preservation administration. He further argued that it is also essential to offer continuing education opportunities in resources' preservation for those whose qualifications need updating or those who wish to build on their existing knowledge.

Feather (1996) has called attention to the proper handling of library materials by all of those involved as a sort of inexpensive measure by any library or archive to begin its 
programmes of preservation, which can, at least, prevent damage to materials which would have been caused by simple ignorance. Similarly, Smith (1993) argued that proper shelving and storage are important factors in extending the life of all books. He also noted that oversize books - inordinately tall, wide, or thick - frequently have bindings that are weak in proportion to their size and weight. They cannot be stored safely on ordinary vertical shelves. Hence, they should be stored flat on broad, fixed shelves of roller shelves, with not more than three or four volumes resting on top of each other. Writing on library book, photocopying processes, Burdick (1993) also noted that "certain styles of copy machines help to minimize damage to bound materials. According to him, V-shaped cradle copiers that allow a volume to be copied while lying face up are not yet widely available, so the best solution is to use a machine that has a copy surface that extends to one outer edge of the machine". Traditionally, libraries and archives independently have undertaken activities to preserve their collections by providing proper housing, protection from mutilation and theft, library binding, and occasional repair and restoration.

Harvey (1993) goes on to describe strategies for preservation, which include: "clearly deterring priorities for preservation, relating preservation actions to institutional objectives, preferring methods which treat materials economic in bulk (such as mass decalcification) over those which apply only to single items, implementing the practices of preventative preservation rather than reliance on "after the event" intervention by conservation, recognizing the important role which education and training plays, and accepting that librarians cannot have the running to conservators but must take their preservation further into their own hands".

Ojo-Igbinoba (1993) in his writing on indigenous methods of preservation in Africa, stressed that apart from fungi, the libraries suffer inconveniences from termites, cockroaches, silverfish, firebrats, bookworms, book lice, moths, spiders, beetles, mud wasps and rodents. He goes further to state that most of the indigenous methods for combating fungal and insect attacks in the libraries were first formulated by expatriate libations, and the formulates were based on mercuric chloride, phenol, "Ogogoros" (as alcohol) and methylamines sprays.

According to Jones (2011), one of the primary problems confronting library profession is lack of commitment by the available human resources, particularly, in the areas of information and communication technologies (ICTs) and preservation of resources on cultural heritage. The knowledge explosion brought about by the acceleration of scientific and technological progress is adding a new dimension to education, cap (Jones 2001).acity building, amongst other essential human development endeavours. Librarians, irrespective of their levels in the professional hierarchy must possess the conceptual knowledge, skills and attitudes relevant to the performance of their jobs. Training refers to the manifestation of knowledge, skills and attitudes in a person which enables him to apply them in his work situation. In essence, education is to cause a permanent change in behaviour potential of the concerned individual and it is regarded as the key with which to unlock the stores of knowledge and for their use by the society. As a result of its importance for professional upliftment, libraries have often tried to inculcate some desirable professional orientations in their personnel through training.

According world Bank (1998), reports that, special efforts are required to understand, document and disseminate IK for preservation, transfer or adaptation elsewhere. IK is mostly tacit or embedded in practices and experiences of the people and it is usually showed through personal communication and demonstration. To this point, recording tacit knowledge, transferring and disseminating it, is therefore a challenge on its own. Moreover, documenting IK requires 6 capacity in terms of skills, expertise and financial resources.IK faces the critical challenge of scientific validation reports. IK practitioners are expected to provide documented 
evidence of the efficacy of their claims in academic journals. However, much of IK is rooted in oral traditions and is not systematically documented in written form (Magga, 2005). Also, not all aspects of living traditions of IK can be captured as artifacts using technology .Such a situation poses some challenges to the libraries that have traditionally been granting access to materials in a site-specific location (Okore, Ekere\& Eke, 2009).

Burtis (2009) notes that, there is a discord between LIS professionals and indigenous peoples, remarking that IK and traditional cultural expressions are represented in Library and archival collections, but often LIS professionals make no attempt to put them into a cultural context. "In support of intellectual freedom, we skillfully catalogue, digitize and display information so that the public can access it", though, a noble goal, Wendland (2008) cited in Burtis (2009) however remarks that indigenous claims for greater protection of indigenous knowledge systems and cultural materials lie, albeit perhaps only superficially, at right-angle to some of the core objectives of libraries and other information services. Moreover, libraries are also facing competition with community structures such as tele-centers which are becoming important platforms for capturing, transferring and giving access to IK (Okore, Ekere\& Eke, 2009).

For indigenous communities, IK are not things that exist separately from their culture notes Burtis corroborating the earlier stance of Mabawonku (2002). The discord with LIS systems, however, lies in the orientation of the field toward a scientific topic of information retrieval and information access (Burtis, 2009). Thus, knowledge becomes information, divorced from the context in which it was created .This process allows indigenous cultural capital to be co-modified in the name of intellectual freedom fronted by the LIS profession..

Bradley (2005), argues that libraries, museums and other cultural institutions are committing increasing amounts of time and money to digitization in order to improve access to their collections.

In a plea for the development of digitization skills in existing staff, Jones (2001) maintained that:

Digital projects require new skills. Project planning should allow new technologies, even if an outside vendor completes a project or a new staff is hired specifically to work on a digital project, permanent. Staff should at least learn the basic theories and practices of digitization. Institutions often hire short-term staff for digitization projects which can result in the loss of digital expertise when the project ends.

Jones (2001) identified the benefits of digital access for collections as follows:

- Easy to be viewed from anywhere, at any time of the day.

- Can be readily printed from the web.

- Viewers can find what they are looking for quickly and independently.

- Save staff reference time by answering frequently asked questions on the web.

- Electronically enhanced images can be viewed with greater legibility.

- Increased use of collections and facilitated learning and scholarship.

The preservation benefits for collections include:

- Objects do not have to be reshelf or located by staff.

- Objects are not handled frequently thereby reducing wear and tear.

\section{METHODOLOGY}

The researchers used the survey research design in assessing the professional competence of librarians in the preservation of cultural heritage. The institutions covered include: Bishop 
Stuart University, Mbarara University of Science and Technology, Makerere University, Uganda Christian University and Uganda Matyrs University.

Structured questionnaire, designed and constructed by the researchers was the instrument used for data collection. The questionnaire was finally administered to the respondents. However, not all the respondents returned the duly completed questionnaire. Out of 12 copies of unused questionnaire, 5 were not returned at all, while the remaining 7 were not properly filled and therefore discarded. Analysis was therefore based on 66 well completed and returned questionnaire. The data collected were analyzed and tabulated using ratio, mean and percentages.

\section{Findings}

A basic breakdown of the demographic characteristics and designations of the survey respondents provided key fundamental information for interpreting the survey results. For a snapshot of the results, see table 1 .

Table 1 Institutions used for the study

\begin{tabular}{|c|c|c|}
\hline Institution & No. of respondents & Percentage (\%) \\
\hline UCU & 23 & 34 \\
\hline MUST & 4 & 6 \\
\hline BSU & 5 & 8 \\
\hline Makerere University & 34 & 52 \\
\hline Total & 66 & 100 \\
\hline
\end{tabular}

Table 2 Years of Experience

\begin{tabular}{|c|c|c|c|c|c|c|c|}
\hline Institution & 1-5yrs & 6-10yrs & 11-15yrs & 16-20yrs & 21-25yrs & 26-30yrs & 31yrs - \\
\hline UCU & 12 & 7 & 6 & 5 & 2 & 2 & - \\
\hline MUST & 6 & 10 & 2 & - & 1 & 3 & 1 \\
\hline BSU & - & 4 & 1 & - & - & - & - \\
\hline MUK & 2 & - & - & 1 & 1 & - & - \\
\hline Total & 20 & 21 & 9 & 6 & 4 & 5 & 1 \\
\hline
\end{tabular}

The librarians were asked to indicate the years they had worked as academic librarians. Table 2 indicated that $20(30 \%)$ had been academic librarians for 1-5 years, with 21 others $(32 \%)$ for $6-10$ years, another $9(14 \%)$ for $11-15$ years, $6(9 \%)$ for $16-20$ years, $4(6 \%)$ for 21 25 years, while $5(8 \%)$ has worked for $26-30$ years and only $1(2 \%)$ has worked for 31 years and above.

\section{Designation}

Concerning the ranks of the participants, $16(21 \%)$ were Assistant Librarians, $13(22 \%)$, Librarians II, whereas 9 (15\%) were Librarians I, 2 (5\%) were Senior Librarians, 14 (24\%) were Principal Librarians while $5(8 \%)$ were Deputy University Librarians.

The researcher wondered if the respondents were choosing training programs opportunities that would help them on their professional duties. Overall, the whole participants, 100 percent (66) had formal education, 83 percent or 55 had attended workshop, similarly, 88 percent (58) indicated that they had attended seminars, whereas, 78 percent or 52 had participated in on the job training, 44 percent or 29 of the respondents had mentoring from their senior colleagues with 44 percent or 29 being trained through e-learning and job rotation at 72 percent or 48 .

When asked the type of sponsorship they got for the training programme, the overwhelming majority of 79 percent (52) indicated that they were sponsored by the 
university, 73 percent (48) replied that they were self-sponsored. 7 respondents (7percent) indicated that they were sponsored by the non-governmental bodies. The next questions asked the participants were to indicate how satisfied they were with the trainings they received. Only 28 percent (19) were "very satisfied", more than half of the respondents, 53 percent (35) opined that they were "satisfied', 17 percent (11) of the respondents indicated "not satisfied" while none indicated 'undecided'.

The researcher also explored the training programme that has tremendous impact on their knowledge of preservation of library materials. On workshop, 28 percent (18) indicated "strongly agree", 45 percent (24) showed "agree" while 18 percent (12) showed "Disagree" while only 9 percent (6) opted for "strongly disagree". With regards to seminars, 27 percent (15) indicated "strongly agree", 45 percent opted for "agree", while 9 percent (5) showed 'disagree', 13 percent (7) indicated "strongly disagree". With regard to the issue of e-learning, 17 percent (8) says "strongly agreed", 40 percent (19) indicated "agree". 36 percent indicated "disagree" and only 6 percent (3) says "strongly disagree".

When asked to evaluate the impact the training had on their job, 49 percent (21) indicated "strongly agree", more than half 58 percent (25) opted for "agree' 14 percent (6) indicated for 'disagree'; only 2 percent (1) of the respondents indicated 'strongly agree". On formal education, 54 percent (32) of the respondents opted for "strongly agree", 37 percent (22) responded "agree", and 7 percent (4) of the respondents indicated "disagree" only 2 percent (1) opted for "strongly agree".

On the issue of cultural heritage available in the research institutions, artifacts attracted the highest percentage of 42; this is closely followed by images from books (39 percent), songs (35 percent) and photographic slides. Some have more than one as their cultural heritage that is why it is more than $100 \%$.

The respondents were invited to select methods they use in preserving their library resources.

Table 3 Methods used in preserving library resources

\begin{tabular}{|l|c|c|c|c|}
\hline \multicolumn{1}{|c|}{ Preservation methods } & Very often & Often & Occasionally & Never \\
\hline Binding of loose sheets & $63 \%$ & $25.9 \%$ & $9.5 \%$ & $1.6 \%$ \\
\hline Microfilming & $2.5 \%$ & $17.5 \%$ & $25 \%$ & $55 \%$ \\
\hline Photocopying & $41.9 \%$ & $35 \%$ & $19 \%$ & $4.1 \%$ \\
\hline Deacidification & $5 \%$ & $12.8 \%$ & $18 \%$ & $64 \%$ \\
\hline Digitization & $20 \%$ & $38.7 \%$ & $26.5 \%$ & $14 \%$ \\
\hline
\end{tabular}

With regards to preservation methods used, table 3 reveals that 63 percent indicated that they use loose sheets "very often", 26 percent (16) indicated "often", while 10 percent opted for occasional and only 2 percent indicated "never". On the use of microfilming, 3 percent (1) indicated 'very often', 18 percent (7) says 'often', 25 percent (10) opted for occasional which the majority of 55 percent (22) indicated 'never". On use of photocopying as preservation method, 42 percent (26) indicated that they use photocopying for preservation of cultural heritage very often. 20 percent () indicated 'often', 10 percent (6) says 'occasional' while only 2 percent (1) opted for 'never' on the use of de-acidification only 5 percent (2) indicated 'very often', 13 percent (5) says 'often" while 18 percent (7) opted for 'occasional', majority of the respondents 65 percent (25) says "never". On digitization of library resources, 20 percent opted for "very often", while 39 percent (19) indicated "often", 27 percent (13) opted for 'occasional', while only 14 percent says "never" (7).

When asked if their institutions have started digitization of their cultural heritage resources, only two out of the four university libraries studied have started. MUST and 
Uganda Christian University while the other two Makerere and Bishop Stuart University are yet to start. Respondents' answer to the question on materials digitized in UCU includes crafts, images from books, artifacts, photographic slides, these and other research works. On the other hand MUST have only digitized images from books, theses and other research works. With regards to effectiveness of the digitization process in the affected institutions, 41 percent (13) reported very effective, 53 percent (17) indicated effective, only 6 percent (2) opted for not effective in UCU. While in MUST, 31 percent (4) indicated "very effective" and 69 percent (9) indicated "effective".

Table 4 Constraints in Digitization/Preservation

\begin{tabular}{|l|c|c|c|c|}
\hline \multicolumn{1}{|c|}{ Constraints in Digitization/Preservation } & Strongly Agree & Agree & Disagree & $\begin{array}{c}\text { Strongly } \\
\text { Disagree }\end{array}$ \\
\hline Cost of digitization & 34 & 19 & 12 & 1 \\
\hline Inadequate infrastructure facilities & 37 & 27 & 2 & - \\
\hline Trained manpower & 23 & 34 & 6 & 3 \\
\hline Non-existence of software & 9 & 6 & 22 & 38 \\
\hline Harsh environmental condition & 5 & 14 & 21 & 26 \\
\hline
\end{tabular}

To better understand the constraints in digitization as a means of preservation vis-à-vis experiences by these institutions, several statements were proposed and the respondents' options were recorded. As shown in table 4, thirty four (34) respondents chose "strongly agree" on cost of digitization. On inadequate infrastructure facilities, thirty seven (37) respondents indicated "Strongly Agree". On trained manpower, thirty four (34) respondents indicated "Agree". With regard to the option on non -existence of software, the majority (38) of them said "strongly disagree". On harsh environmental conditions" twenty six (26) indicated "Strongly Disagree".

On how the situation could be improved, 75 percent (44) opted for "strongly agree", and 25 percent (14) opted for "agree", for training of librarians, provision of adequate digitization infrastructure attracted 70 percent (40) which indicated "strongly agree" 30 percent (17) opted for "agree". On the issue of adequate funding 80 percent (45) choose "strongly agree", while only 20 percent (11) says "agree". Next is on proper handling of library materials, the majority of the respondents, 58 percent (33) indicated "strongly agree", with only 42 percent (24) opted for "agree". On ensuring favorable environmental condition, 60 percent (33) opted for "strongly agree", 36 percent (20) indicated "agree", while only 4 percent (2) indicated "disagree". On the provision of large bandwidth to ensure network connectivity, 62 percent (32) indicated "strongly agree" and 38 percent (20) opted for "agree".

\section{DISCUSSION}

The use of mentoring and e-learning to develop library staff remains unpopular and not significant, as only 29 out of 66 respondents opted for them. Formal education, workshop and seminar seem to be popular among the listed options. This may be attributed to the fact that most of these are in-house. According to Ajidahun (2007), this latter outcome is because university libraries cannot afford to release their staff to go back to school, either for part- or full-time studies.

Thus, it is cheaper to allow library staff to attend these training in-house. Training is unlikely to be effective as long as the personnel policies and systems of the university do not support the activity. For example, if training is not integrated with the career development plans of librarians and systems for performance evaluation, it is unlikely that "effective demand" for training will be created. The reluctance of the government to sponsor people for training and the lack of motivation on the part of librarians to take advantage of training 
opportunities could largely be attributed to the reasons for paucity of continuing professional development activities among librarians. The analysis indicated that most of the respondents were satisfied with the progress made at the training. Also, the result indicated that the impacts made on the trainees were enormous. These were most felt at the workshops and were closely followed by formal education and then seminars.

From the analysis, the cultural heritage resources available in some of the studied institutions include: songs, crafts, moral, historical sites, artifacts, works of arts and cultural, archaeological sites, photographic slides, folklore, and images from books. Of all the preservation methods previously listed in table 3, binding of loose sheets seems to be mostly used. This is closely followed by photocopying and the least was microfilming. As rightly observed by Milevski and Nainis (1993), book repair is a preventive maintenance activity. It anticipates potential damage to library materials and it provides corrective treatments to protect them from deterioration in the future, photocopying seems also to be very popular among libraries.

Important rare materials are photocopies by libraries as a form extending the life span of such materials. One of the reasons libraries photocopy is economic-based. Most materials are so scarce and expensive that not all libraries can afford to buy them, therefore, photocopying to save cost.

Digitization seems not to be too popular in these libraries. This may be attributed to cost of digitization. Developing a digital surrogate of a rare or fragile original object can provide access to users while preventing the original from damage, handling or display. This was the motivation behind the digitization of many priceless artifacts, most famously the Beowulf manuscript at the British library which is too fragile for use or consultation by scholars without special permission. As noted earlier two of the studied institutions are not yet into digitization. Works being digitized by MUST and UCU include crafts, images from books, artifacts, photographic slides, thesis and research works.

The two institutions involved in digitization reported that the methods they used are effective. According to Hughes (2004: 228), it is important to recognize that there is no best approach and indeed no best camera or scanner for image digitization. No single device can accommodate the wide range of physical formats in library, archives and museum's collections because the dexterity of the camera or expertise of the scanner operator varies considerably and more so that handling guidelines, image quality requirements, budgets and time tables are project specific.

In order to restructure the constraints in digitization, inadequate infrastructure, manpower shortfall and non-existence of software, respondents recommended amongst others, training of librarians on methods of digitization of cultural heritage resources, provision of adequate infrastructures, adequate funding and ensuring favorable environmental conditions.

\section{CONCLUSION}

There is no doubt that preservation of Uganda's cultural heritage resources is very important to the development of the various cultures. It is a witness of where we have come from and where we are. This was rightly stated by Williams (2001), "preservation of cultural heritage resources is essential to sustainable development. It recognizes the importance of cultural continuity and of human history in nourishing social cohesion, a sense of self,of belonging, and of place in a context within which to understand the past and to contemplate the future". This task underscores the required capacity building in preservation techniques and commitment of librarians to preserve the various cultural heritage resources in their custodies. 


\section{RECOMMENDATIONS}

- Training of Librarians - With the sporadic changes in the information network, it is absolutely imperative that continuing professional development of librarians should be given priority. Since these librarians serve divergent needs of users in their respective libraries, it is important that these professionals should be conversant with how to preserve and access relevant information. So management should consider this important function of developing their personnel to ensure effective service delivery.

- Provision of infrastructure - Every organization stands on three pillars of capital, human and material resources to support its functions. For the library to develop properly they need not only human but also material resources such as infrastructure which will help the library to carry out its operations. For instance, librarians need to be trained on digitization of library materials; for the training to be effective, the necessary facilities for effective learning should be available. Also when the training has been completed, they need these skill enhancing facilities to work with for permanence of the knowledge and skills acquired during the learning process.

- Adequate funding - for the effective functioning of the library, adequate fund is needed especially to get the best out from the two other factors (human and material resources). Where adequate fund is provided, training of librarians and equipping of the library will be effectively achieved and this will enhance the whole process of digitization of library materials.

- Environmental conditions constitute a lot to the preservation of library resources. Both harsh and humid weather adversely affects library materials. To ensure the preservation of the cultural heritage resources, they should be stored in air-conditioned rooms with moderate the temperature and electric fans to avoid hotness of the environment.

- Provision of internet infrastructure with large bandwidth to ensure adequate network connectivity.

- Integrating heritage resources in contextual community development by building in incentives for the local population to protect the heritage.

\section{REFERENCES}

[1] Ajidahun, C.O. (2007). The training, development and education of library manpower in information technology in university libraries in Nigeria. World Libraries 17 (1).

[2] Appleby, P.C. (1991). Modern business administration. London: Pitman.

[3] Vondracek, R. (2006). Organising for digitization: A survey. Portal: Libraries and the Academy 6(2): 197-217.

[4] Ekere, F.C., \&Ekere, J. (2008).Contemporary challenges facing library and information science professions in Nigeria. In Harvey, R. (1997).The peservation of electronic records.

[5] In Gorman, G.E., \& Milles, R.H. (Eds.) Collection management for the $21^{\text {st }}$ century: A handbook for librarians. London:

[6] The Greenwood Library Management Collection. Jones, T. (2001). An introduction to digital projects for libraries, museums, \& archives (http://images.library.uiuc.edu \resources\introduction.htm)

[7] Ojo-Igbinoba, M.E. (1993). The practice of conservation of library materials in SubSaharan Africa. Indiana: Africa StidiesProgram, Indiana University. 
[8] Singh, R. (2004). Restructuring library and information science curriculum. LIS Education in India.

[9] Smith, M.A. (1987). Care \& handling of bound materials. In Preservation of Library Materials. Conference Library held at the National Library of Austria, Vienna, April $7^{\text {th }}$ $10^{\text {th }}, 1986$ (ed) merrily Smith, IFLA Publications 40-41 (2): 45-53.

[10] UNESCO (1995). Our cultural diversity. World Commission on Culture and Development. Paris: UNESCO. 